From carbon nanostructures to new photoluminescence sources: an overview of new perspectives and emerging applications of low

\title{
pressure PECVD
}

${ }^{(1)}$ Dr. Francisco J. Gordillo-Vázquez * ${ }^{*}$ Dr. Víctor J. Herrero, and ${ }^{(2)}$ Dr. Isabel Tanarro

(1) Instituto de Óptica, CSIC, Serrano 121, 28006 Madrid, Spain

(2) Instituto de Estructura de la Materia, CSIC, Serrano 123, 28006 Madrid, Spain

Low pressure plasma enhanced chemical vapour deposition (PECVD) is a powerful and versatile technique used for thin film deposition and surface treatment since the early sixties of the last century. However, its application away from the different stages of microelectronic circuit fabrication is not far in time. In recent years, PECVD is experiencing emerging applications due to new materials and processes requirements in a wide diversity of areas like the biomedical sector, solar cell industry, fuel cell development, fusion research or, to mention just a few, the synthesis of silicon nanocrystals showing efficient photoluminescence, useful for future solid state light sources. These new scenarios have stimulated further development of novel PECVD diagnostic techniques together with fundamental experimental and theoretical studies aimed to better understand some of the basic processes underlying the plasma-surface interaction. This paper gives an overview of some new research areas where PECVD is finding promising applications.

Keywords: nanoparticles, plasma, biomedical, novel diagnostics, PECVD 
** FJGV acknowledges partial financial support from CSIC-CAM (Project No. 200550M016 and 200650M016) and MEC (Projects No. MAT2006-13006-C02-01 and ENE2006-14577-C04-03), VJH and IT acknowledge funding from MEC (Projects No. FTN-2003-08228-C03-03, FIS2004-00456 and ENE2006-14577-C0403)

\section{Introduction}

The early papers by S. W. Ing ${ }^{[1-3]}$ and co-workers published between 1963 and 1965 on low temperature plasma enhanced CVD (or simply PECVD) deposition of silicon oxide films could be considered as one of the first experimental reports on the possibility of using electric discharges in gases to produce plasmas that generate different type of reactive species for thin film deposition. These initial attempts were used for microelectronic applications and, in particular, for diffusion masks and passivation. In this regard, the introduction in $1974^{[4]}$ of commercial batch processing reactors was a definite step for serious consideration of plasmaassisted deposition processes in microelectronic circuit production lines. With time, low pressure plasma deposition of inorganic films such as silicon-based semiconductors and insulators have been gradually moving out of the integrated circuit (IC) industry to new applications in solar cell, ${ }^{[5]}$ thin film transistors ${ }^{[6,7]}$ flatpanel displays or micro-electromechanical systems (MEMS) ${ }^{[8]}$ More recently, the superior optical properties of nanocrystalline silicon (nc-Si:H) in comparison with those of hydrogenated amorphous silicon $(\mathrm{a}-\mathrm{Si}: \mathrm{H})$ have stimulated research on nanostructured silicon films for photovoltaic applications. ${ }^{[9-13]}$ The interest of silicon nanoparticles extends to the production of single electron transistors, ${ }^{[14]}$ new memory devices, ${ }^{[15]}$ quantum dot lasers ${ }^{[16]}$ and especially new solid state light sources based on the efficient room temperature photoluminescence of silicon nanocrystals ${ }^{[17-21]}$ produced by low pressure PECVD. 
Apart from the plasma synthesis of inorganic films, the first two reports on the synthesis of carbonaceous films by plasma assisted CVD date back to 1976 . These two papers employed low pressure DC ${ }^{[22]}$ and RF $(13.56 \mathrm{MHz})^{[23]}$ discharges to decompose mixtures of ethylene/argon and methane/argon, respectively. In 1985, the work by Matsumoto ${ }^{[24]}$ and co-workers showed the first evidence of the synthesis of polycrystalline diamond films from low pressure MW (2.45 GHz) methane/molecular hydrogen plasmas. Further investigations starting in the late 80s of the last century up to now have shown the feasibility of using RF and MW-driven low pressure PECVD to produce different kind of carbon-based nanostructures (nano ${ }^{[25-27]}$ or ultrananoparticles, ${ }^{[28]}$ nanotubes, ${ }^{[29]}$ nanowalls $^{[30]}$ or nanotips ${ }^{[30]}$ ) from a mixture of a hydrocarbon gas (or $\mathrm{H}$-free precursors like $\mathrm{C}_{60}$ ) and other functional gases $\left(\mathrm{H}_{2}, \mathrm{~N}_{2}, \mathrm{NH}_{3}\right.$, $\left.\mathrm{Ar}, \mathrm{He} \ldots\right)$.

Systematic investigation of plasma polymerization started only in the 60s of last century after the pioneer work published by J. Goodman in $1960^{[31]}$ showing the relevant dielectric properties of one micron thick film of polymerized styrene deposited by plasma. Soon after this, in 1969, the work by J. R. Hollahan ${ }^{[32]}$ and coworkers experimentally proved the possibility to use low pressure ammonia plasmas to produce amino groups able to attach to the surfaces of different polymers with the goal of producing new materials compatible with human blood. Since then, intensive research has been carried by using low pressure PECVD for a variety of biomedical applications.

In the following sections of this review, we will cover some of the many emerging fields where low pressure PECVD is having a renewed and key interest in surface treatment and film deposition (see Figure 1) together with the description of novel diagnostic tools for PECVD and recent advances in fundamental research. 
We will begin this review with basic issues and then we'll move on to specific applications.

\section{Surface processes in reactive plasmas}

The interaction between the plasma and the deposition substrate in PECVD involves in general a large amount of concurrent intertwined processes, ${ }^{[33-}$ ${ }^{36]}$ whose combined effects are difficult to unravel. The interplay between deposition and erosion ultimately responsible for film growth, and the actual morphology and properties of the formed films, are often determined by synergies between several of the participating species which are in turn dependent on the physical characteristics of the plasma and of the substrate. Despite many efforts by different groups, the basic mechanisms are often poorly known and the optimization of film growth for technical applications is usually dealt with empirically. However, over the last years, detailed studies using a variety of experimental techniques, involving notably molecular beams and lasers, are beginning to shed some light on the key species and processes involved in plasma-surface interactions for some relevant cases. We will comment here briefly on some of these recent achievements.

The main reactive species interacting with the surface are ions and radicals (including atoms). Although in the low temperature, weakly ionized plasmas employed for PECVD, radicals are usually the dominant growth precursors, ions can also influence the deposition process in several important ways: they can contribute to film growth either by direct implantation or by creating reactive sites on the surface, and they can also erode the film by physical sputtering (see Figure 2). The most abundant radicals in the gas phase do not necessarily play an important role in PECVD. Actual growth precursors will typically have high sticking coefficients and much lower gas phase concentrations. The search for growth 
precursors in deposition plasmas requires thus the use of sensitive detection techniques for radicals. An overview of plasma diagnostics techniques is given in the next section. Whenever possible, a simultaneous monitorization of gas phase composition and film growth is desirable.

In recent times, the basic physicochemical mechanisms responsible for the deposition of amorphous hydrogenated carbon (a-C:H) films in methane plasmas have been investigated thoroughly by Jacob, von Keudell and co-workers in a series of works combining different experimental techniques. ${ }^{[35,37-45]}$ In addition to the primary radicals formed in the dissociation of the precursor $\left(\mathrm{CH}_{3}, \mathrm{CH}_{2}, \mathrm{CH}, \mathrm{C}\right)$, secondary reaction products generated in the course of plasma reactions can be also directly incorporated to the growing film. In this respect, the important role of unsaturated hydrocarbon radicals, in particular $\mathrm{C}_{2} \mathrm{H}$ and $\mathrm{C}_{2} \mathrm{H}_{3}$ with high sticking coefficients should be stressed. Refined particle beam experiments ${ }^{[43]}$ have shown that $\mathrm{H}$ atoms and ions can largely enhance the adsorption probability of a given radical through the production of chemisorption sites, especially dangling bonds, on otherwise hydrogen terminated surface. This effect is especially marked in the case of $\mathrm{CH}_{3}$, whose sticking coefficient can increase from $10^{-4}$ to $10^{-2}$. In spite of this enhancement, the sticking coefficient remains low and consequently, methyl radicals reach relatively large concentrations in the gas phase, but do not play usually an important role in film growth. Finally, low-energy carbonaceous ions impinging on the growing film have also high sticking probabilities and can contribute to film growth. These ions do not produce appreciable sputtering effects for energies below $\approx 500 \mathrm{eV}$. The prevalence of a given growth precursor or mechanism has been found to be closely related to the mean energy dissipated by source gas molecule in the plasma, $E_{\text {mean. }}{ }^{[45]}$ For $E_{\text {mean }}$ values $<10 \mathrm{eV}$, film growth 
is mainly caused by incorporation of $\mathrm{CH}$ radicals (see Figure 3). For intermediate energies, higher hydrocarbon radicals $\left(\mathrm{C}_{2} \mathrm{H}, \mathrm{C}_{2} \mathrm{H}_{3}\right)$ are the dominant growth precursors, and only for values of $\mathrm{E}_{\text {mean }}$ larger than $100 \mathrm{eV}$, carbonaceous ions begin to contribute appreciably to film growth.

Plasma surface interactions have also deserved much attention in fluorocarbon (FC) plasmas, which find widespread application in the etching of Si and $\mathrm{SiO}_{2}$ and in the deposition of fluorocarbon films. In general there is a delicate balance between deposition and etching that depends sensitively on the precursor and on the type of discharge used. In early works, it was suggested that $\mathrm{CF}_{2}$ might be the main precursor of film growth. ${ }^{[46,47]}$ However, it was later shown that under polymerizing conditions the radical has a long lifetime and reaches a high concentration indicative of a low sticking probability. Experiments using space and time resolved laser induced fluorescence (LIF) and absolute calibration techniques ${ }^{[48,49]}$ have established that $\mathrm{CF}$ and $\mathrm{CF}_{2}$ radicals are produced essentially at the surfaces, and that the actual film precursors are oligomers of the $\mathrm{C}_{\mathrm{x}} \mathrm{F}_{\mathrm{y}}\left(\mathrm{CF}_{2}\right)_{\mathrm{n}}$ type formed in gas phase polymerization reactions of the relatively abundant $\mathrm{CF}_{2}$ radicals. The production of $\mathrm{CF}_{2}$ at the surface of the forming $\mathrm{FC}$ films, and the low sticking probability of the radical were also observed by Fisher and co-workers, ${ }^{[50]}$ who conducted detailed experiments on different plasma precursors using the “imaging of radicals interacting with surfaces” (IRIS) technique, ${ }^{[51]}$ which combines molecular beams and LIF imaging methods. The enhancement in $\mathrm{CF}_{2}$ production through ion bombardment has also been investigated by this group. ${ }^{[50,52]}$ Other aspects of the behaviour of $\mathrm{CF}_{\mathrm{x}}$ radicals in fluorocarbon plasmas are presently studied by various groups. ${ }^{[53,54]}$ 
The surface reactivity of other radicals has also been studied using the IRIS technique. ${ }^{[55]}$ In particular $\mathrm{CH}, \mathrm{SiH}$ and $\mathrm{CN}$ were found to be "sticky" with high surface reactivity, whereas $\mathrm{NH}$ and $\mathrm{SiCl}_{2}$ do not tend to stick to the surface of growing films. The authors of these studies indicate a possible correlation between surface reactivity and electronic structure of the radicals: species with a doublet electron configuration are found to have a high reactivity whereas those with a singlet configuration tend to be generated at the surface during film deposition. These findings warrant further experimental and theoretical work in order to corroborate this correlation and to provide insight into the underlying mechanisms.

Growth mechanisms have also been investigated in recent times for the deposition of films of $\mathrm{SiC}_{\mathrm{x}} \mathrm{N}_{\mathrm{y}}$ ternary compounds. ${ }^{[56]}$ In low voltage RF discharges, $\mathrm{SiH}_{3}$ and $\mathrm{C}_{2} \mathrm{H}$ radicals are deemed to contribute independently to the carbon nitride and silicon nitride networks. In high voltage glow discharges, bonds between the three components are apparently formed by subplantation and damage-induced disorder, giving rise to harder films.

A sound understanding of the physical chemistry behind PECVD will require a theoretical description of, at least, the most relevant plasma surface interactions, which are much more complicated than their gas phase counterparts. Progress in the theoretical treatment of the surface has led to models incorporating different growth structures ${ }^{[36]}$ or the effects of ion bombardment on the growing films. ${ }^{[57]}$ However theoretical models are still relatively rudimentary and have no predictive power due to, in most cases, a lack of proper verification and validation of computational simulations. Progress in this field is also severely hampered by the lack of reliable kinetic data (either from experiment or theory) for many of the elementary processes involved. 


\section{Diagnostic techniques}

So far, the development of plasma processing has mostly been carried out by a trial and error method changing external parameters such as power, pressure and gas mixture ratios, basically dependent on the reactor, whereas the inside state of the plasma was unknown; nevertheless, the processes of interest can be characterized much more properly employing internal parameters such as ion and radical densities and their energies. To obtain a complete set of the main plasma properties, several complementary experimental techniques are available.

There exist a very high number and variety of plasma diagnostic methods and only a brief overview will be given here. A scheme including some of them is given in Figure 4. As entities that are intrinsically light emitting sources, plasmas can be characterized first of all by emission spectroscopy. This technique has been used during decades to identify the existing species with a high degree of confidence and sensitivity; nevertheless it can hardly provide estimations of species concentrations. In order to get reliable relative concentrations from emission data, recent diagnostics improvements and a more precise knowledge of excitation cross sections ${ }^{[58,59]}$ have opened new possibilities and alternatives ${ }^{[60,61]}$ to the formerly well established method of actinometry.

Broadband light emitting sources like cyclotron radiation and high resolution laser sources extending from the MW to the VUV region have stimulated noticeably the use of direct absorption spectroscopic techniques from ground and excited levels to study the electronic, vibrational and rotational molecular transitions, providing direct and detailed information about absolute concentrations of the detected species and their characteristic temperatures, which may be far from 
equilibrium and differ for the different energy modes. High power lasers, pulsed or continuous, have also allowed the development of other very sensitive techniques such as LIF and resonance-enhanced multiphoton ionization (REMPI). In ref. [62] a valuable compilation of spectroscopic data and references for polyatomic ions and neutral transients is given, including comments about the specific detection techniques. An interesting description of the presently most employed spectrometric methods for the detection of radicals can be found in ref. [63]. Among the presently available experimental methods based in the use of lasers for plasma diagnostics, diode laser absorption and the very sensitive technique of cavity ring-down spectroscopy ${ }^{[64,65]}$ have experienced great advances during the last years. The recently developed quantum cascade lasers operating with short IR pulses at room temperature are very promising mid-infrared radiation sources for plasma characterization. ${ }^{[66,67]}$ All of these spectroscopic methods have the great advantage of being non-intrusive. Nevertheless, the geometry of the reactor should be frequently adapted to the diagnostic technique to be used, and this is not always the case in production reactors. For example, long optical path lengths (single or in multipass configuration) are needed for absorption spectroscopy of transient species which appear at very low densities in the plasma.

Electron temperature, plasma density and plasma potential are measured with electric (Langmuir) probes inserted into the plasma. In this case, special care should be paid to minimize the perturbations caused by the probes on the original plasma conditions. Continuous improvements of this method for different kinds of plasmas are being developed. A recent and complete revision on the use of electrical probes is found in ref. ${ }^{[68]}$ 
Mass spectrometry of ions with analysis of the ion energy distribution functions, ${ }^{[69,70]}$ ion attachment mass spectrometry, ${ }^{[71]}$ the use of different isotopes and mass spectrometry at threshold energies for radical detection, ${ }^{[72,73]}$ are also very useful tools for plasma diagnostics, which have added new possibilities to the conventional mass spectrometry of neutral stable species with ionization by electron impact, where the detection of minor products has been mostly hampered by overlapping signals with peaks proceeding from the fragmentation patterns of compounds present at higher concentrations.

Fiber-optic catalytic probes of different materials are beginning to be used to measure the dissociation degree of pure gases such as $\mathrm{H}_{2}, \mathrm{O}_{2}$ or $\mathrm{N}_{2}$ in the afterglow of plasma reactors. ${ }^{[74]}$ Dust particles formed in the plasmas, which are getting increasing attention because of their influence in the final quality of the treated surfaces, are now monitored by light scattering. ${ }^{[75]}$ In this way, a very characteristic periodic increase and decrease of dust density and average size has been found, even in non modulated discharges, controlled by gravity. On the other hand, on/off plasma modulation, which controls in time the concentrations of short lived species, allows the application of several of the former mentioned diagnostic techniques to time resolved plasma studies, ${ }^{[76]}$ which add valuable information on reaction coefficients and wall reaction probabilities ${ }^{[77]}$ and opens new insights in deposition processes with minimum dust production. ${ }^{[78]}$

Concerning plasma surface interactions, a recent simple method to determine surface loss probabilities employs a dismountable cavity with a small entrance slit exposed to the reactive species, ${ }^{[44]}$ which allows a later study of the deposited materials in the internal surfaces. Ion and neutral particle-beam experiments allow a much more detailed determination of sticking coefficients. ${ }^{[43]}$ 


\section{Nanofabrication and quantum confinement structures.}

Nanostructured materials are expected to bring about major advances in electronics and photonics in the course of the next decades. ${ }^{[79]}$ In nanometer-sized semiconductors and metals, the de Broglie wavelength of the electrons and holes becomes comparable to the dimensions of the relevant crystallites and the valence and conduction bands may split into discrete electronic levels whose spacing, as well as that of the band-gap, increases with decreasing particle size. ${ }^{[80]}$ Quantized matter can adopt different shapes (dots, wires, ...) depending on the quantization dimensions. Several procedures have been devised for the production of nanoscaled materials, including colloid chemistry, self assembly, lithographic etching, and thin film deposition. The use of reactive plasmas as a versatile nanofabrication tool has been recently reviewed by Ostrikov. ${ }^{[30]}$

In general, in nanofabrication processes adequate building units must be generated, transported and stacked onto suitably prepared surfaces. PECVD provides often a good opportunity for the generation of a large variety of building units. Besides the molecules present in the feedstock gases, atoms, ions and radicals are generated by electron impact or by subsequent chemical reactions. In addition, negative ions within the plasma are confined by the plasma sheath and can eventually reach relatively high concentrations and give rise to polymerization and clustering through reactions with other plasma species. In contrast, the number of building units in thermal CVD, without ions or clusters, is more limited and deposition rates are significantly slower than in PECVD. Another advantage of plasma assisted deposition over CVD is the fact that ion bombardment can activate surface sites for reaction without the need to heat the substrate. With an adequate choice of the feedstock gases and type of discharge, one can favour the formation of 
deposition precursors suitable for each case. Given the low pressures typical of most PECVD reactors, very few collisions take place in the plasma sheath and, once generated, the smaller building units travel undisturbed to the substrate; the larger building units (>1 nm) can be subject to drag or thermophoretic forces, that can be used advantageously for the control of the deposition process. ${ }^{[81]}$ In general, for good quality films the building units should not disintegrate or damage the surface upon landing.

The production of silicon and carbon based nanoassemblies are the most thoroughly studied plasma assisted nanofabrication processes and, although the basic mechanisms responsible for the formation of the various structures remain largely unknown, general rules and practical recipes are available in the literature. ${ }^{[30]}$ Reactive carbon dimers, $\mathrm{C}_{2}$, are known, for instance, to be efficient for the growth of carbon nanotubes (CNTs) because they can insert easily into the hexagonal units of the graphene sheets that build the CNT walls (see below). Charged carbon clusters in the nanometer scale can be very adequate for the synthesis of single crystalline diamond or of crystalline graphite. ${ }^{[30]}$ In contrast to $\mathrm{CH}_{3}$, whose sticking coefficient was seen to be small in general, ${ }^{[44]}$ the $\mathrm{SiH}_{3}$ radical, which has a pyramidal structure, contributes efficiently to the growth of a-Si:H. ${ }^{[35,82]}$ Large silanes and hydrogenated Si clusters play also a key role in the PECVD of nanostructured amorphous silicon films for solar cell applications. In some cases, the size and concentration of clusters in the discharge has been correlated with the microstructural parameters defining the film quality. ${ }^{\left[{ }^{83]}\right.}$ Nanoparticles generated in the plasma can be also incorporated into the growing films. Polymorphous silicon (pm-Si:H), which is formed by an amorphous matrix with nanocrystalline inclusions and can lead to a significant improvement of the performance of solar cells, has been obtained with this 
procedure. ${ }^{[84,85]}$ A recent computational study suggests that the formation of crystalline hydrogenated Si nanoparticles could be favoured by the use of hotter silane plasmas. ${ }^{[86]}$

Quantum effects can be appreciable for 1-10 nm sizes and thus single crystalline nanoparticles formed in reactive plasmas constitute good building blocks for quantum confinement structures of interest in molecular electronics, but quantum confinement structures can also be formed from smaller building units. $\mathrm{Xu}$ et $a .^{[87]}$ have recently reported the development of an integrated plasma-aided nanofabrication facility (IPANF) based on RF discharges and its application to the production of carbon nanotips (see Figure 5), semiconductor high aspect (height to width) ratio nanowires and quantum dots of $\mathrm{Si}, \mathrm{SiC}$ and $\mathrm{Al}_{1-\mathrm{x}} \mathrm{In}_{\mathrm{x}} \mathrm{N}$.

In the following two sections we will comment in some more detail on the plasma assisted production and applications of Si and C-based nanostructures. Other examples of nanofabrication processes by PECVD can be found in the recent review article by Ostrikov. ${ }^{[30]}$

\section{New applications of silicon nanoparticles}

\subsection{Solar cells}

The limitations of present amorphous silicon (a-Si:H) solar cells have stimulated new avenues of research for finding novel materials. An important alternative comes from microcrystalline silicon films grown by low pressure very high frequency $(60-70 \mathrm{MHz})$ PECVD. ${ }^{[88]}$ The work published by J. Meier ${ }^{[89]}$ and co-workers in 1994 showed that $\mu \mathrm{c}-\mathrm{Si}: \mathrm{H}$ has the potential to become a new photovoltaic thin film material. However, the typical deposition rates obtained by Meier were too low ( $1 \AA \mathrm{s}^{-1}$ ) to be compatible with industrial applications. The 
recent work by M. Kondo ${ }^{[90]}$ reports $\mu \mathrm{c}-\mathrm{Si}: \mathrm{H}$ growth rates of $1.5 \mathrm{~nm} / \mathrm{s}$ with conventional RF (13.56 MHz) at relatively low pressure (2-4 Torr) and up to almost $4 \mathrm{~nm} / \mathrm{s}$ (preserving a good crystallinity and relatively low substrate temperature of $250{ }^{\circ} \mathrm{C}$ ) using a $60 \mathrm{MHz}$-excited plasma-assisted CVD equipment. It is important to stress that the latter results were obtained by implementing novel control of plasma and surface reactions by a combination of plasma parameters and different electrode configuration. In this regard, the film crystallinity was monitored by using Optical Emission Spectroscopy (OES) of the emission intensities of excited atomic hydrogen and silicon atoms in the plasma. ${ }^{[90]}$

Very recently, new low pressure PECVD configurations, like the single ring-like RF electrode ${ }^{[20]}$ or the so-called low energy PECVD (or simply LEPECVD), have been used to deposit single-crystal silicon nanoparticles ${ }^{[20]}$ or nanocrystalline silicon (nc-Si:H) thin films of potential application in solar cells ${ }^{[13,91]}$. The use of LEPECVD has allowed achieving films of high homogeneity with demonstrated growth rates of $1 \mathrm{~nm} \mathrm{~s}^{-1}$ on substrates kept at temperatures around $250^{\circ} \mathrm{C} .{ }^{[91]}$ However, further improvement of this promising technique might need study of in-situ plasma conditions.

Finally, it is also worth mentioning the research done by E. S. Aydil and collaborators in connection with the mechanism of hydrogen-induced crystallization from an amorphous silicon film structure to a nanocrystalline structure obtained from non-thermal $\mathrm{SiH}_{4} / \mathrm{H}_{2}$ plasmas. ${ }^{[11-13]}$ The crystallization process is produced by the insertion of $\mathrm{H}$ atoms into strained $\mathrm{Si}-\mathrm{Si}$ bonds through the formation of intermediate bond-centred $\mathrm{Si}-\mathrm{H}-\mathrm{Si}$ configurations as the $\mathrm{H}$ atoms diffuse through the a-Si:H films. Subsequent structural relaxation of these Si-Si bonds results in the transformation of the film's structure from amorphous to nanocrystalline. ${ }^{[11-13]}$ 


\subsection{Solid state light sources of the future}

Since the first experimental results of $1988^{[92]}$ and $1990^{[93]}$ reporting important room temperature photoluminescence (PL) from nanocrystalline silicon (< $5 \mathrm{~nm}$ ), intense research has been conducted towards the development of new (costeffective and more efficient) methods for high-yield production of silicon nanocrystals. The latter would considerably accelerate the appearance of many new applications, including more efficient solid state light sources based on silicon nanocrystals. Although the liquid ${ }^{[94]}$ and gas-phase ${ }^{[95]}$ approaches investigated by different groups are partially successful in producing silicon nanocrystals, they failed in achieving high-yield production and narrow particulate size distribution, respectively. The main drawback (particle agglomeration) of gas-phase processes is strongly reduced (keeping an efficient yield) by using low pressure non-thermal plasmas produced in PECVD processes. Different groups ${ }^{[96-99]}$ have used the latter approach for the synthesis of silicon nanocrystals from plasmas of silane highly diluted in argon. However, only a very recent contribution ${ }^{[21]}$ by the group of $U$. Kortshagen, working with the appropriate electrode configuration of a low pressure argon-silane flow through PECVD reactor, has shown the feasibility of achieving high ensemble quantum yields (of up to $62 \%$ at around $789 \mathrm{~nm}$ ) of silicon quantum dots avoiding surface oxidation of the sample. In spite of this, many unknowns remain as, for example, how to extend such promising high quantum yields to lower wavelengths.

\section{Carbon-based nanostructures}

Since the first report published in $1989^{[25]}$ on low pressure RF (13.56 $\mathrm{MHz}$ ) methane/argon plasma assisted CVD synthesis of single nanodiamond 
crystals $(10 \mathrm{~nm}-40 \mathrm{~nm})$ within a polycrystalline and/or an amorphous carbon matrix on room temperature silicon substrates, considerable research efforts have been conducted toward the investigation of new carbon-based nanostructures. The discovery of carbon nanotubes by S. Iijima in $1991^{[100,101]}$ was an important milestone in the further world-wide interest in nanostructured carbon materials (see Figure 6). CNTs are a kind of elongated fullerenes, with extraordinary electronic and mechanical properties, which can have diameters smaller than $1 \mathrm{~nm}$ and lengths of several microns. They can be single-walled or multiwalled, and are formed by graphene sheets constituted by hexagonal rings of carbon atoms. They are usually obtained by arch discharge, laser ablation, or chemical vapour deposition (both thermal and plasma assisted). ${ }^{[29,102,103]}$ Among these procedures of synthesis, CVD methods can be easily scaled up and allow a better control of the geometry of arrays for electronic applications.

The fabrication of CNT by CVD requires a catalyst, usually a first row transition metal (Fe, Ni, Co), to promote nanotube growth and a gaseous phase containing “activated carbon” species. A wide variety of feedstock substances can act as carbon sources including methane, acetylene and carbon monoxide, but also liquid hydrocarbons and carbon clusters derived from solid samples. The properties and shapes of the fabricated nanotubes can in principle be tailored by an adequate choice of feedstock, catalyst and reactor. Many different reactor configurations are being used nowadays for the synthesis of single walled and multi-walled carbon nanotubes. ${ }^{[29,103]}$

Although both thermal CVD and PECVD are commonly used in the synthesis of CNTs, the plasma assisted deposition can offer sometimes important advantages for the control of size, shape and pattern uniformity in the synthesis of 
selected nanoassemblies. An illustrative example is the alignment of CNTs perpendicular to the substrate. The work by Y. Chen and co-workers ${ }^{[104]}$ showed for the first time in 1997 that the use of plasma assisted CVD techniques allowed the growth of well-aligned carbon nanofibres. Low pressure PECVD has also been recently used for the synthesis of large-area ordered patterns of single crystal carbon nanotips ${ }^{[105,106]}$ acting as nanoemitters, of great interest for the emerging electronemitter display technology. The relation between this preferential alignment and the plasma field was clearly established by Bower et al. ${ }^{[107]}$ in nanotubes grown from a microwave discharge of acetylene and ammonia (see Figure 7). When the growth was performed under thermal CVD conditions (i.e. without the plasma), the degree of alignment was much lower. Recent model calculations of the formation of carbon nanotip microemitter structures by Levchenko and co-workers, ${ }^{[108-110]}$ which take into account, both the gas phase dynamics ${ }^{[109]}$ and the surface self-organization ${ }^{[108]}$, can account for the higher aspect ratio, and thus higher potential emission yield, of the nanotips formed by PECVD. The pronounced vertical alignment obtained in the carbon nanostructures grown by plasma assisted techniques is due, at least in part, to the fact that the electric field at the plasma sheath, which focuses on the growth spots, drives the charged building units and polarizes neutral building units, aligning them to stack in the nanoassembly, preferentially from the top. The role of the electric field in the vertical alignment of growing carbon nanotubes has also been confirmed in a combined experimental and computational study by Bell et al. ${ }^{[111]}$.

After the discovery of the nanotubes, experimental studies by Gruen and co-workers showed that, contrarily to previous works using a mixture of $\mathrm{H}_{2}$ and some kind of hydrocarbon precursor, it was possible to grow diamond and microdiamond thin films with MW (2.45 GHz) PECVD from a relatively low 
pressure $\left(<150\right.$ Torr) $\mathrm{C}_{60} /$ Ar plasma without the addition of hydrogen or oxygen. ${ }^{\text {[26, }}$ ${ }^{112]}$ Detailed and systematic experiments carried out by Zhou et al. ${ }^{[113]}$ with MW $\mathrm{CH}_{4}(1 \%) / \mathrm{H}_{2} / \mathrm{Ar}$ and $\mathrm{C}_{60} / \mathrm{Ar}$ plasmas showed a transition from microdiamond to nanodiamond (and ultrananocrystalline diamond) with the presence, in the latter case, of strong Swan band emission related to $\mathrm{C}_{2}$ radicals. The factors, especially the gas pressure and $\mathrm{Ar}$ concentrations, leading to the transition from micro to nanocrystallinity have been experimentally studied in MW systems by Zhou et al. ${ }^{[113]}$ and Goyette et al. ${ }^{[114,115]}$ Optical emission spectroscopy of the plasma showed dramatic changes in the species emission pattern as the $\mathrm{Ar}$ concentration increases. ${ }^{[113]}$ This leads one to think that changes in the nonequilibrium plasma chemistry are likely to occur parallel to the surface changes leading from micro-to nanodiamond structures. While much experimental evidence points to $\mathrm{C}_{2}$ dimers as the growth species for nanocrystalline diamond in $\mathrm{MW} \mathrm{CH}_{4}(1 \%) / \mathrm{H}_{2} / \mathrm{Ar}, \mathrm{C}_{2} \mathrm{H}_{2}(1$ $\%) / \mathrm{H}_{2} / \mathrm{Ar}$ and $\mathrm{C}_{60} / \mathrm{Ar}$ plasmas, no definitive growth mechanism of diamond with $\mathrm{C}_{2}$ as the growth species has been established so far. Further work by Carlisle ${ }^{[116]}$ and co-workers adding $\mathrm{N}_{2}$ to $\mathrm{CH}_{4} / \mathrm{Ar}$ plasmas allowed the synthesis of highly conducting (five orders of magnitude above undoped samples) nitrogen-doped ultrananocrystalline diamond films of interest for applications in electronic devices. Very recently, Carlisle ${ }^{[117]}$ and co-workers have also reported the first successful result on the synthesis (by low pressure PECVD) of self-assembled hybrids of ultrananocrystalline diamond and carbon nanotubes (see Figure 8). This new material might have new properties not yet explored that can be of high technological interest.

Fundamental experimental work by Winter's ${ }^{[118,119]}$ group has been carried out on the discharge dynamics and growth precursors of nanocarbon 
particles formed during low pressure RF (13.56 MHz) PECVD with $\mathrm{CH}_{4} / \mathrm{Ar}$ and $\mathrm{C}_{2} \mathrm{H}_{2} / \mathrm{Ar}$ plasmas. This group was able to establish analogies between deposited amorphous carbon nanoparticles and the material found in the carbonaceous interstellar medium. $^{[120,121]}$

Finally, it should be added that, in spite of the strong experimental research and considerable success on the synthesis of new nanocarbon structures with low pressure PECVD, the diagnostics and modelling of these systems have only received a small attention. ${ }^{[109,122-124]}$ However, since traditional trial and error approaches are usually expensive and time-consuming, diagnostics and detailed modelling of both the plasma and plasma-surface interactions are required for a deeper understanding of the processes which will translate in a faster solution of present day obstacles that prevent further progress in the production of nanodevices based on carbon nanostructures.

\section{Fuel cell materials}

Fuel cells are generally categorized by their membrane electrolyte, that is, the material sandwiched between the two electrodes. This material's characteristics determine the optimal operating temperature and the fuel used to generate electricity. Out of the six main types of fuel cells, the so-called Polymer Electrolyte Membrane Fuel Cell (PEMFC including Direct Methanol Fuel Cell (DMFC)) more commonly known as proton exchange membrane fuel cell or simply PEM is one of the most promising fuel cells types for widespread use. PEM fuel cell uses an advanced plastic electrolyte (usually Nafion ${ }^{\circledR}$ ) to transport protons from the anode to the cathode. The PEM's solid electrolyte is much easier to handle and use than the liquid electrolytes, and its low operating temperature $\left(<80^{\circ} \mathrm{C}\right)$ allows a quick start-up. Both the electrodes and the membrane electrolytes are expected to be 
optimized by using low pressure PECVD ${ }^{[125]}$. Recent results show that when PEM electrodes deposited with PECVD are used with hydrogen, the power densities delivered are comparable to the ones achieved with commercial electrodes. However, the key difference provided by PECVD is the ability to control the catalyst concentration profile within the electrode allowing the lowering of the catalyst content in almost one order of magnitude with respect to commercial electrodes. The latter improves the fuel cell efficiency considerably. ${ }^{[126]}$

Nafion ${ }^{\circledR}$ membranes are made of a conductive perfluorinated hardcore containing sulfonic groups. However, apart from its high cost, its main drawbacks (limiting the practical application of PEMFC) are its thickness, high methanol permeability and low mechanical strength (both due to the negligible intermolecular cross linked structure of the polymer skeleton). Different investigations ${ }^{[127-131]}$ have explored the possibility of using capacitively coupled reactors at about 0.3 Torr for plasma polymerization leading to the deposit of thin films (about $1 \mu \mathrm{m}$ ) characterized by their highly cross-linked structure, high proton conductivity and low methanol permeability. In addition, the thin plasma deposited membranes are a plus, since they guarantee a good membrane-electrode contact which is responsible of the attainable power density. ${ }^{[126]}$ The ionic conductivities of the plasma polymerized films depend on the external plasma parameters used. In this regard, plasma polymer films prepared in glow discharge were found to have considerably lower conductivities than those prepared in afterglow discharges (under soft plasma conditions). ${ }^{[120]}$ However, most of the results (except those of $\mathrm{Mex}^{[132]}$ ) indicate that, in general, ionic conductivities of films prepared by PECVD are much smaller than that of Nafion ${ }^{\circledR}$. In any case, the lower conductivity of plasma deposited membranes is compensated by their difference in thickness. The latter decisively contributes to 
the fact that plasma membranes synthesised in the afterglow mode have lower specific resistances than $\mathrm{Nafion}^{\circledR}$, that is, the real efficiency for proton conductivity of plasma deposited membranes is better than that of the commercial membranes. [125]

One of the main problems regarding practical use of Direct Methanol Fuel Cells is the crossover (high permeability) of methanol through the conventional polymer electrolyte membrane used. In this regard, recent results by $\mathrm{H}$. Y. $\mathrm{Ha}^{[133]}$ and co-workers using low pressure ( 1 mTorr - 0.5 Torr) PECVD to prepare a Nafion ${ }^{\circledR} /$ nano-silica composite membrane of variable thickness (controlled by the deposition time) have revealed that the ion conductivity of the composite membrane containing a $10 \mathrm{~nm}$ nano-silica film was similar to the unmodified $\mathrm{Nafion}^{\circledR}$ membrane, while its methanol permeability went down to $40 \%$. In addition, the fuel cell performance of the composite membrane with the $10 \mathrm{~nm}$ layer of nano-silica was up to $20 \%$ higher than that of the bare Nafion ${ }^{\circledR}$ membrane. ${ }^{[133]}$ The reason for such improvement is not yet clear but the strategy of using PECVD has shown strong potential for depositing very thin films of nano-silica on commercial membranes.

\section{Controlled fusion research}

PECVD has also found widespread application in controlled fusion research. An efficient control of plasma-wall interactions is crucial for the performance of fusion devices (tokamaks and stellarators). Advantages and disadvantages of the various plasma facing materials are thoroughly discussed in literature ${ }^{[134,135]}$. Most fusion reactors have metallic walls in the main vessel and carbon based (graphite or carbon composites) limiters and divertors. Contamination 
of the fusion plasma by high atomic number (high Z) materials can give rise to high energy losses by radiation and, therefore, prior to operation, the first (metallic) wall of the reactor is generally coated with low $\mathrm{Z}$ elements which have a low plasma radiation rate and minimize energy losses. PECVD of suitable precursors in glow discharges extended over the whole vessel is usually employed for first-wall coating (see Figure 9). Initially, a-C:H layers were used. ${ }^{[136]}$ These layers have excellent mechanical, optical, electrical and chemical properties, but give problems with the recycling of hydrogen and can be eroded by oxygen, leading to CO. In order to overcome these shortcomings, new films incorporating low $\mathrm{Z}$ oxygen getters like $\mathrm{B}$, $\mathrm{Li}$ or $\mathrm{Si}^{[137]}$ have been developed over the last decade. These new films have allowed a significant reduction of the oxygen contamination and have also improved $\mathrm{H}$ recycling. In particular, the deposition of a-B/C: $\mathrm{H}$ films (boronization) has been applied in many fusion devices (see refs [138-140] and the references cited therein). The efficiency of these types of coatings often depends critically on the precursor (usually boranes or carborane) and on the particular coating conditions. There is at present an active research on the production and properties of better quality boron containing films. ${ }^{[141-143]} \mathrm{Li}$ based coatings ${ }^{[144-146]}$ have been less used thus far due to technical difficulties for the deposition of homogeneous films. An efficient PECVD scheme has not yet been achieved and Li is either evaporated or exposed to the hot plasma for coating. Present evidence suggests that Li based coatings have better properties than B for hydrogen recycling. In addition they can improve significantly the resistance to chemical erosion of the graphite elements in the reactor. ${ }^{[147]}$ Although $\mathrm{B}$ and Li coatings reduce appreciably the concentration of unwanted plasma impurities, there are still controversies about their influence on plasma confinement or their effect on reactor power ${ }^{[134]}$ that warrant further studies on the 
characteristics of these films and on their interaction with neutral and charged plasma species.

As mentioned above, in most fusion devices various kinds of graphite and other carbon composites are used in the parts of the reactor exposed to the largest thermal shocks (limiters or divertors). Chemical erosion of these materials, when exposed to high particle fluxes of hydrogen isotopes, leads to the formation of re-deposited carbon films (see ref [44] and references therein) that can incorporate fuel particles up to a ratio $\mathrm{C} / \mathrm{H}(\mathrm{D}, \mathrm{T})$ of $1: 1$, especially after the divertor, where cold plasmas are formed (see Figure 9). Under real operation, the formation of tritiated deposits would lead to the activation of inaccessible parts of the fusion device. The difficulty of tritium removal by in-situ techniques represents a major drawback for the extensive use of carbon in a fusion reactor ${ }^{[134,135]}$ and there is great interest in inhibiting the formation of these unwanted films. In the coating of metallic walls with a-C:H films there is always a competition between deposition and erosion. In plasmas of pure hydrocarbons, the atomic hydrogen produced in the dissociation of the precursor leads already to some chemical erosion removing part of the film, but this removal can be largely enhanced by the addition of other species. In this respect, the introduction of small amounts of $\mathrm{N}_{2}$ under conditions compatible with the operation of fusion devices, has been shown to be very promising. ${ }^{[69,148-150]}$ The exact mechanism of inhibition is not known but it seems to be related to the formation of strong NC bonds either in the gas phase or at the surface, which compete with CC bonds and give rise to volatile species that can be pumped away. ${ }^{[149]} \mathrm{N}_{2}{ }^{+}$ions have been shown to have a good efficiency for the chemical sputtering of a-C:H films, ${ }^{[151]}$ which can be greatly enhanced in the presence of $\mathrm{H}$ atoms. ${ }^{[152]}$ In addition, the deposition channel might also be affected by other gas 
phase or surface processes. ${ }^{[69,149,152]}$ Encouraging results, with moderate reductions of carbon redeposition, have been already obtained in nitrogen injection experiments in the divertor region of fusion devices. ${ }^{[149,150]}$

\section{Biomedical applications}

Low temperature plasmas have led to new applications for the surface treatment of biomedical devices, which benefit from the experience in plasma physics and chemistry gained in other more matured areas such as microelectronics. Recent developments in plasma coating can enhance the fatigue strength and the corrosion and wear resistance of biomaterials, as well as their tribological and mechanical properties. These new advances can also achieve bioactive or bioinert performance, transform a hydrophobic surface into a hydrophilic one, or significantly improve biocompatibility and adhesion between bones, tissues and implants. ${ }^{[153]}$ Proper applications yield dense and pinhole free coatings with excellent interfacial bonds due to the graded nature of the interface, and are compatible with masking techniques to enable surface patterning. ${ }^{[154]}$

Plasma engineering can be applied to non-line-of-sight, irregular sample geometries, as well as to different kinds of implant materials, such as metals, ceramics, composites and polymers, without appreciable thermal loading and without substantially degrading or changing the characteristics of the bulk. Good examples of biomedical implants, considerably improved by plasma surface modification, are presently found in intraocular lenses and artificial corneas, heartvalves, vascular stents, artificial blood vessels and dental and bone implants. Glow discharge equipments are usually very flexible with respect to their operating conditions, so that, with a single equipment, substrate-specific cleaning and 
sterilization processes can be achieved ${ }^{[155]}$ and a wide variety of physico-chemical coating properties can be attained by varying the type of precursors and other parameters. ${ }^{[156]}$

The latest advancements in plasma polymer chemistry at micro and nanoscales, and the use of soft plasma assisted modification techniques, have largely increased the potential for the synthesis of reasonably well defined molecular structures, avoiding, or at least reducing, side reactions such as ionic bombardment, dissociation of the precursor molecule and extensive cross linking. ${ }^{[157]}$ Plasma polymers can be tailored to have considerable elasticity with reversible swelling characteristics, offering a three-dimensional interface for biomolecular immobilization procedures. In addition, these materials have the ability to regulate cell functions such as proliferation, differentiation and apoptosis. By these means, cell culture substrates and scaffolds are designed to mimic the situation in vivo, exhibiting typical macroscopic structures of living tissue. ${ }^{[158]}$

Diamond like carbon (DLC) films are often used in biomedical implants coatings because they possess excellent mechanical properties and can adhere on a range of biomaterials with desirable bulk properties, showing no toxicity toward living cells, no inflammatory response or loss of cell integrity, and no cellular damage. ${ }^{[159]}$ Similarly, CN films are also extremely hard and wear-resistant, and their novel properties are attracting the attention of researchers of various kinds of surgical implants. Nitrogen implanting plasmas on titanium and aluminium prothesis lead to $\mathrm{TiN}$ and $\mathrm{Ti}_{2} \mathrm{~N}$ formation and to $\mathrm{AlN}$ and AlON layers respectively, which render high strength and high wear resistance. Duplex treatments consisting of plasma nitriding and plasma assisted CVD allow tailoring of the surface properties such as wear and corrosion resistance and are especially suitable for 
complex loading. ${ }^{[153]}$ Ammonia plasma incorporates amine and amide groups, which play an important role in endothelial cells adhesion and growth on modified surfaces. ${ }^{[153]}$ In orthopaedic technology, hydroxyapatite (HA) coatings are widely studied because of its close resemblance to the chemical composition ( $\mathrm{Ca} / \mathrm{P}$ ratio) of teeth and bones. Finally, teflon-like films and coatings deposited from organosilicon plasmas are receiving increasing attention. ${ }^{[160]}$

\section{Conclusions and outlook}

In the previous sections, recent achievements and new perspectives of the low pressure PECVD technique have been reviewed. Because of the extension of the field, the review is restricted to a limited number of areas. The main points dealt with in the previous sections are briefly outlined here.

The identification of film growth precursors remains in general a fundamental issue. The variation in the nature of the growth precursors with plasma energy and the relationship between their electronic structure and surface reactivity are being currently investigated with combinations of refined experimental techniques. These investigations have produced interesting results, but leave also many open questions to address in the near future.

Although the main applications of PECVD are usually related with various processes of material fabrication, the technique is also used in other fields. In the realm of controlled fusion, the use of plasmas for first wall coating with low atomic number elements and for the removal of unwanted tritiated deposits constitute active research areas. In some cases, the developments in new materials have a clear aim, like the increase in the biocompatibility of polymers for biomedical applications; but new materials are being constantly generated by 
PECVD and, although some of their properties are immediately recognized, many others remain unexplored, offering attractive possibilities for further investigation. Illustrative examples are hybrids of ultrananocrystalline diamond and carbon nanotubes, or composite fuel cell membranes including nano-silica films.

Particular attention has been paid along the review to novel developments in various fields of nanotechnology, especially of Si and C-based structures, including applications to solar cells and to the production of carbon nanotubes, which hold promise for revolutionary advances in electronics and optoelectronics during the next decades. At present, PECVD research in the production of nanostructures is mainly academic and there are still problems for reliable large-scale industrial production at a competitive cost.

In spite of some recent progress in the diagnostics techniques and in the elucidation of the basic mechanisms responsible for the formation of the deposition products, the improvement of PECVD technologies remains largely empirical. Attempts to bridge the gap between the trial-and-error approach, prevalent in present day applications, and a new strategy, based more heavily on a sound knowledge of the basic physicochemical processes underlying PECVD, will be a major challenge for the next future. Progress along this line must be based on a further development of in in-situ diagnostics techniques, especially for low-concentration unstable species, preferably with space and time resolution, and on an improvement of the plasma models, which must include reliable kinetic data and incorporate realistic treatments of the growing surface structures.

\section{References}

[1] L. L. Alt, S. W. Ing, Jr., K. W. Laendle, J. Electrochem. Soc., 1963, 110, 465. 
[2] S. W. Ing, Jr., W. Davern, J. Electrochem. Soc., 1964, 111, 120.

[3] S. W. Ing, Jr., W. Davern, J. Electrochem. Soc., 1965, 112, 285.

[4] A. R. Reinbergh, Electrochem. Soc. Ext. Abstr., 1974, 6, 19.

[5] D. E. Carlson, C. W. Magee, A. R. Triano, J. Electrochem. Soc.: Solid-State Sci. Technol., 1979, 126, 688.

[6] W. C. O’Mara, Liquid Crystal Flat Panel Displays Manufacturing Science and Technology, VAN NOSTRAND REINHOLD, New York, 1993.

[7] S. Sherman, S. Wagner, J. Mucha, R. A. Gottscho, J. Electrochem. Soc., 1997, 144, 3198.

[8] E. Cianci, A. Schina, A. Minotti, S. Quaresima, V. Foglietti, Sensors and Actuators A, 2006, 127, 80.

[9] R. Martins, H. Aguas, A. Cabrita, P. Tonello, V. Silva, I. Ferreira, E. Fortunato, L. Guimaraes, Solar Energy, 2000, 69, 263 (Suppl. S).

[10] S. Binetti, M. Acciarri, M. Bollani, L. Fumagalli, H. Von Känel, S. Pizzini, Thin Solid Films, 2005, 487, 19.

[11] S. Sriraman, S. Agarwal, E. S. Aydil, D. Maroudas, Nature, 2002, 418, 62.

[12] D. C. Marra, E. A. Edelberg, R. L. Naone, E. S. Aydil, J. Vac. Sci. Technol. A, 1998, 16, 3199.

[13] W. M. M. Kessels, A. H. M. Smets, D. C. Marra, E. S. Aydil, D. C. Schram, M. C. M. Van de Sandem, Thin Solid Films, 2001, 383, 154.

[14] Y. Fu, M. Willander, A. Dutta, S. Oda, Superlatt. Microstruc., 2000, 28, 177.

[15] M. L. Ostraat, J. W. De Blauwe, M. L. Green, L. D. Bell, M. L. Brongersma, J. Casperson, R. C. Flagan, H. A. Atwater, Appl. Phys. Lett., 2001, 79, 433.

[16] L. Canham, Nature, 2000, 408, 411. 
[17] C. Courteille, J. L. Dorier, J. Dutta, C. Hollenstein, A. A. Howling, J. Appl. Phys. 1995, 78, 61.

[18] A. A. Howling, C. Courteille, J. L. Dorier, L. Sansonnens, C. Hollenstein, Pure and Applied Chemistry, 1996, 68, 1017.

[19] Z. Shen, T. Kim, U. Kortshagen, P. H. McHurry, S. A. Campbell, J. Appl. Phys., 2003, 94, 2277.

[20] A. Bapat, C. Anderson, C. R. Perrey, C. B. Carter, S. A. Campbell, U. Kortshagen, Plasma Phys. Control. Fusion, 2004, 46, B97.

[21] D. Jurbergs, E. Rogojina, L. Mangolini, U. Kortshagen, Appl. Phys. Lett., 2006, 88, 233116-1.

[22] D. S. Whitmell, R. Williamson, Thin Solid Films, 1976, 35, 255.

[23] L. Holland, S. M. Ojha, Thin Solid Films, 1976, 38, L17.

[24] O. Matsumoto, H. Toshima, Y. Kanzaki, Thin Solid Films, 1985, 128, 341.

[25] G. Amaratunga, A. Putnis, K. Clay, W. Milne, Appl. Phys. Lett., 1989, 55, 634.

[26] D. M. Gruen, S. Liu, A. R. Krauss, X. Pan, J. Appl. Phys., 1994, 75, 1758.

[27] J. M. López, F. J. Gordillo-Vázquez, J. M. Albella, Appl. Surf. Science, 2002, 185, 321.

[28] A. R. Krauss, O. Auciello, D. M. Gruen, A. Jayatissa, A. Sumant, J. Tucek, D. C. Mancini, N. Moldovan, A. Erdemir, D. Ersoy, M. Gardos, H. Busmann, E. Meyer, M. Ding, Diamond Relat. Mater. 2001, 10, 1952.

[29] M. Meyyappan, L. Delzeit, A. Cassell, D. Hash, Plasma Sources Sci. Technol., 2003, 12, 205.

[30] K. Ostrikov, Rev. Mod. Phys., 2005, 77, 489.

[31] J. Goodman, J. Polym. Sci., 1960, 44, 551. 
[32] J. R. Hollahan, B. B. Stafford, R. D. Fald, S. T. Payne, J. Appl. Polym. Sci., 1969, 13, 807.

[33] A. Grill, Cold Plasma in Materials Fabrication IEEE press, New York 1993.

[34] A. Lieberman, A. J. Lichtenberg, Principles of Plasma Discharges and Material Processing, Wiley, New York 1994.

[35] A. von Keudell, Plasma Sources Sci. Technol., 2000, 9, 455.

[36] C. Cavallotti, M. Di Stanislao, S. Carrà, Prog. Cryst. Growth Charact. Mater., 2004, 48, 123.

[37] C. Hopf, T. Schwarz-Selinger, W. Jacob, A. von Keudell, J. Appl. Phys., 2000, 87,2719

[38] A. von Keudell, T. Schwarz-Selinger, W. Jacob, J. Appl. Phys., 2001, 89,2979.

[39] M. Meier, A. von Keudell, J. Appl. Phys., 2001, 90, 3585.

[40] M. Meier, A. von Keudell, J. Chem. Phys., 2002, 116, 5125.

[41] C. Hopf, A. von Keudell, W. Jacob, J. Appl. Phys., 2003, 93, 3352

[42] C. Hopf, A. von Keudell, W. Jacob, J. Appl. Phys., 2003, 94, 2373.

[43] W. Jacob, C. Hopf, A. von Keusell, M. Meier, T. Schwarz-Selinger, Rev. Sci. Instrum., 2003, 74, 5123.

[44] W. Jacob, C. Hopf, M. Meier, and T. Schwarz-Selinger in Nuclear Fusion Research: Understanding Plasma-Surface Interactions (Eds: R.E.H. Clark and D. Reiter), Springer Series in Chemical Physics Vol. 78, Springer Verlag, Berlin 2005.

[45] M. Bauer, T. Schwarz-Selinger, W. Jacob, A. von Keudell, J. Appl. Phys., 2005, 98, 073302.

[46] M. M. Millard, E. Kay, J. Electrochem. Soc., 1982, 129, 160. 
[47] R. D’Agostino, F. Cramarossa, V. Colaprico, R. d'Ettole, J. Appl. Phys., 1983, $54,1284$.

[48] J. P. Booth, G. Cunge, P. Chabert, N. Sadeghi, J. Appl. Phys., 1999, 85, 3097.

[49] G. Cunge, J. P. Booth, J. Appl. Phys., 1999, 85, 3952.

[50] E. R. Fisher, Plasma Process. Polym., 2004, 1, 13.

[51] P. R. McCurdy, K. H. A. Bogart, N. F. Dalleska and R. E. Fisher, Rev. Sci Instrum., 1997, 68, 1684.

[52] I. T. Martín, J. Zhou, E. R. Fisher, J. Appl. Phys., 2006, 100, 013301.

[53] J. P. Booth, H. Abada, Chabert, D. B. Graves, Plasma Sources Sci. Tech., 2005, 14, 273.

[54] F. Gaboriau, G. Carty, M. C. Peignon, C. Cardinaud, J. Phys. D: Appl. Phys., 2006, 39, 1830.

[55] D. Liu, I. T. Martín, J. Zhou, E. R. Fisher, Pure Appl. Chem., 2006, 78, 1187.

[56] I. V. Afanasiev-Charkin, M. Nastasi, J. Appl. Phys., 2004, 96, 7681.

[57] D. Zhang, M. J. Kushner, J. Apppl. Phys., 2000, 87, 1060.

[58] B. P. Lavrov, M. Osiac, A. V. Pipa, J. Röpcke, Plasma Sources Sci. Technol., 2003, 12, 576.

[59] I. Méndez, F. J. Gordillo-Vázquez, V. J. Herrero, I. Tanarro, J. Phys. Chem. A, 2006, 110,6060 .

[60] A. Gicquel, M. Chenevier, K. Hassouni, A. Tserepi, M. Dubus, J. Appl. Phys., 1998, 83, 7504.

[61] M. Kogelschatz, M. Cunge, N. Sadeghi, Eur. Phys. J. Appl. Phys., 2006, 33, 205.

[62] M. E. Jacox, J. Phys. Chem. Ref. Data., 2003, 32, 1.

[63] M. Hori, T. Goto, Plasma Sources Sci. Technol., 2006, 15, S74.

[64] G. Berden, R. Peeters, G. Meijer, Int . Rev. Phys. Chem., 2000, 19, 565. 
[65] R. Z. Martínez, M. Metsälä, O. Vaittinen, T. Lantta, L. Halonen, J. Opt. Soc. Am. B, 2006, 23, 727.

[66] G. D. Stancu, A. V. Pipa, G. Lombardi, P. B. Davies, A. Gicquel, B. P. Lavrov, J. Röpcke, Contrib. Plasm. Phys., 2005, 45, 358.

[67] A. Cheesman, J. A. Smith, M. N. R. Ashfold, N. Langford, S. Wright, G. Duxbury, J. Phys. Chem. A, 2006, 110, 2821.

[68] V. I. Demidov, S. V. Ratynskaia, K. Rypdal, Rev. Sci. Instrum., 2002, 73, 3409

[69] F. L. Tabarés, D. Tafalla, I. Tanarro, V. J. Herrero, A. M. Islyaikin, Vacuum, 2004, 73, 161.

[70] M. Castillo, I. Méndez, A. M. Islyaikin, V. J. Herrero, I. Tanarro, J. Phys. Chem. A, 2005, 109, 6255.

[71] T. Morimoto, S. G. Ansari, K. Yoneyama, T. Nakajima, A. Masuda, H. Matsumura, M. Nakamura, H. Umemoto, Jap. J. Appl. Phys., 2006, 45, 961 and refs. therein.

[72] P. Kaenune, J. Perrin, J. Guillon, J. Jolly, Plasma Sources Sci. Technol., 1995, 4, 250.

[73] M. M. Sanz, L. Abad, V. J. Herrero, I. Tanarro, J. Appl. Phys., 1992, 71, 5372.

[74] M. Mozetic, A. Vesel, U. Cvelbar, A. Ricard, Plasma Chem. Plasma Process., 2006, 26, 103.

[75] J. Berndt, S. Hong, E. Kovacevic, I. Stefanovic, J. Winter, Vacuum, 2003, 71, 377.

[76] M. Castillo, V. J. Herrero, I. Méndez, I. Tanarro, Plasma Sources Sci. Technol., 2004, 13, 39.

[77] I. Tanarro, T. de los Arcos, C. Domingo, V. J. Herrero, M. M. Sanz. Vacuum , 2002, 64, 457. 
[78] S. Hong, J. Berndt, J. Winter, Surf. Coat. Technol., 2003, 174, 754.

[79] B. Yu, M. Meyyappan, Solid-State Electr., 2006, 50, 536.

[80] S. M. Remann, M. Manninen, Rev. Mod. Phys., 2002, 1283

[81] M. Shiratani, S. Maeda, K. Koga, Y. Watanabe, Jpn. J. Appl. Phys. Part 1, 2000, 39, 287.

[82] J. Perrin, M. Shiratani, P. Kae-Nune, H. Videlot, J. Jolly, J. Guillon, J. Vac. Sci. Technol. A, 1998, 16, 278.

[83] M. Shiratani, K. Koga, Y. Watanabe, Thin Solid Films, 2003, 427, 1.

[84] G. Viera, M. Mikikian, E. Bertrán, P. Roca i Cabarrocas, L. Boufendi, J. Appl. Phys., 2002, 92, 4684.

[85] A. Fontcuberta i Morral, P. Roca i Cabarrocas, C. Clerc, Phys. Rev. B, 2004, 69, 125307.

[86] H. Vach, Q. Brulin, N. Chaabane, T. Novikova, P. Roca i Cabarrocas, B. Kalache, K. Hassouni, S. Botti, L. Reining, Comput. Mat. Sci., 2006, 35, 216.

[87] S. Xu, K. Ostrikov, J. D. Long, S. Y. Huang, Vacuum, 2006, 80, 621.

[88] M. Faraji, S. Gokhale, S. M. Choudhari, M. G. Takwale, S. V. Ghaisas, Appl. Phys. Lett., 1992, 60, 3289.

[89] J. Meier, R. Flückiger, H. Keppner, A. Shah, Appl. Phys. Lett., 1994, 65, 860.

[90] M. Kondo, M. Fukawa, L. Guo, A. Matsuda, J. Non-Crystalline Solids, 2000, 266-269, 84.

[91] M. Acciarri, S. Binetti, M. Bollani, A. Comotti, L. Fumagalli, S. Pizzini, H. von Känel, Solar Energy Materials \& Solar Cells, 2005, 87, 11.

[92] S. Furukawa, T. Miyasato, Jpn. J. Appl. Phys., Part 2, 1988, 27, L2207.

[93] L. T. Canham, Appl. Phys. Lett., 1990, 57, 1046. 
[94] M. Nayfeh, O. Akcakir, J. Therrien, Z. Yamani, N. Barry, W. Yu, E. Gratton, Appl. Phys. Lett., 1999, 75, 4112.

[95] P. E. Batson, J. R. Heath, Phys. Rev. Lett., 1993, 71, 911.

[96] S. Oda, M. Otobe, Mater. Res. Soc. Symp. Proc., 1995, 358, 721.

[97] C. R. Gorla, S. Liang, G. S. Tompa, W. E. Mayo, Y. Lu, J. Vac. Sci. Technol. A, 1997, 15, 860.

[98] G. Viera, S. Huet, M. Mikikian, L. Boufendi, Thin Solid Films, 2002, 403-404, 467.

[99] L. Mangolini, E. Thimsen, U. Kortshagen, Nano Lett., 2005, 5, 655.

[100] S. Iijima, Nature, 1991, 354, 56.

[101] Y. Ando, S. Ijima, Jpn J. Appl. Physics, 1993, 32, L107

[102] Y. Ando, X. Zhao, T. Sugai, M. Kumar, Materials Today, 2004, October, 22.

[103] M. L. Terranova, V. Sessa, M. Rossi, Chem. Vap. Depossition, 2006, 12, 315.

[104] Y. Chen, Z. L. Wang, J. S. Yin, D. J. Johnson, R. H. Prince, Chem. Phys. Lett., 1997, 272, 178.

[105] K. Ostrikov, Z. Tsakadze, P. P. Rutkevych, J. D. Long, S. Xu, I. Denysenko, Contrib. Plasma Phys., 2005, 45, 514.

[106] K. Ostrikov, I. Denysenko, M. Y. Yu, S. Xu, Phys. Scr., 2005, 72, 277.

[107] C. Bower, W. Zhu, O. Zhou, Appl. Phys. Lett., 2000, 77, 830.

[108] I. Levchenko, O. Baranov, Vacuum, 2006, 89, 033109.

[109] I. Levchenko, K. Ostrikov, M. Keidar, S. Xu, J. Appl. Phys., 2005, 98, 064304.

[110] I. Levchenko , K. Ostrikov, M. Keidar, S. Xu, Appl. Phys. Lett., 2006, 89, 033109.

[111] M. S. Bell, K. B. K. Teo, R. G. Lacerda, W. I. Milne, D. B. Hash, M. Meyyappan, Pure Appl. Chem., 2006, 78, 1117. 
[112] D. M. Gruen, S. Liu, A. R. Krauss, J. Luo, X. Pan, Appl. Phys. Lett., 1994, 64, 1502.

[113] D. Zhou, D. M. Gruen, L. C. Qin, T. G. McCauley, A. R. Krauss, J. Appl. Phys., 1998, 84, 1981.

[114] A. N. Goyette, J. E. Lawler, L. W. Anderson, D. M. Gruen, T. G. McCauley, D. Zhou, A. R. Krauss, J. Phys. D: Appl. Phys., 1998, 31, 1975.

[115] A. N. Goyette, J. E. Lawler, L. W. Anderson, D. M. Gruen, T. G. McCauley, D. Zhou, A. R. Krauss, Plasma Sources Sci. Technol., 1998, 7, 149.

[116] S. Bhattacharyya, O. Auciello, J. Birrell, J. A. Carlisle, L. A. Curtiss, A. N. Goyette, D. M. Gruen, A. R. Krauss, J. Schlueter, A. Sumant, P. Zapol, Appl. Phys. Lett., 2001, 79, 1441.

[117] X. Xiao, J. W. Elam, S. Trasobares, O. Auciello, J. A. Carlisle, Adv. Mater., 2005, 17, 1496.

[118] S. Hong, J. Berndt, J. Winter, Plasma Sources Sci. Technol., 2003, 12, 46.

[119] E. Kovacevic, I. Stefanovic, J. Berndt, J. Winter, J. Appl. Phys., 2003, 93, 2924.

[120] I. Stefanovic, E. Kovacevic, J. Berndt, Y. Pendleton, J. Winter, Plasma Phys. Control. Fusion, 2005, 47, A179.

[121] E. Kovacevic, I. Stefanovic, J. Berndt, Y. Pendleton, J. Winter, The Astrophysical Journal, 2005, 623, 242.

[122] D. Hash, M. Meyyappan, J. Appl. Phys., 2003, 93, 750.

[123] F. J. Gordillo-Vázquez, J. M. Albella, Plasma Sources Sci. Technol., 2004, 13, 50.

[124] G. Lombarda, K. Hassouni, F. Bénédic, F. Mohasseb, J. Röpcke, A. Gicquel, J. Appl. Phys., 2004, 96, 6739. 
[125] P. Brault, S. Roualdès, A. Caillard, A. L. Thomann, J. Mathias, J. Durand, C. Coutanceau, J. M. Léger, C. Charles, R. Boswell, Eur. Phys. J. Appl. Phys., 2006, 34, 151.

[126] H. A. Gasteiger, J. E. Panels, S. G. Yan, J. Power Sources, 2004, 127, 162.

[127] N. Inagaki, S. Tasaka, T. Kurita, Polym. Bull., 1989, 22, 15.

[128] Z. Ogumi, Y. Uchimoto, K. Yasuda, Z. I. Takehara, Chem. Lett., 1990, 19, 953.

[129] Y. Uchimoto, E. Endo, K. Yasuda, Y. Yamasaki, J. Electrochem. Soc., 2000, 147, 111.

[130] K. Yasuda, Y. Uchimoto, Z. Ogumi, Z. I. Takehara, J. Electrochem. Soc., 1994, 141, 2350.

[131] C. J. Brumlik, A. Parthasarathy, W. J. Chen, C. R. Martin, J. Electrochem. Soc., 1994, 141, 2273.

[132] L. Mex, N. Ponath, J. Müller, Fuel Cell Bulletin, 2001, 39, 9.

[133] D. Kim, M. A. Scibioh, S. Kwak, I-H. Oh, H. Y. Ha, Electrochemistry Communications, 2004, 6, 1069.

[134] G. Federici, C. H. Skinner, J. N. Brooks, J. P. Coad, G. Grisolia, A. A. Haasz, A. Hassanein, V. Philipps, C. S. Pitcher, J. Roth, W. R. Wampler, D. G. Whyte,. Nucl. Fusion, 2001, 41, 1967

[135] G. Federeici, P. Andrew, P. Barabaschi, J. Brrooks, R. Doerner, A. Geier, A. Herrmann, G. Janeschitz, K. Krieger, A. Kukushkin, A. Loarte, R. Neu, G. Saibene, M. Shimada, G. Strohmayer, M. Sugihara, J. Nucl. Mater., 2003, 313, 11.

[136] J. Winter, J. Nucl. Mater., 1987, 131, 145. 
[137] L. L. Peng, E. Y. Wang, N. M. Zhang, D. H. Yan, M. X. Wang, Z. W. Wang, B. Q. Deng, K. H. Li, J. L. Luo, L. Liu, Nuclear. Fus., 1998, 38, 1137.

[138] I. Buzhinskij, M. Semenets , Fus. Technol., 1997, 32 ,1

[139] D. Tafalla, F. L. Tabarés, Vacuum, 2002, 67, 393.

[140] T. Nakano, S. Higashijima, H. Kubo, J. Yagyu, T. Arai, N. Asakura, K. Itami, J. Nucl. Mater., 2003, 313-316, 149.

[141] O. I. Buzhinskij, V. G. Otroshchenko, D. G. Whyte, M. Baldwin, R. W. Conn, R. P. Doerner, R. Seraydarian, S. Luckhardt, H. Kugel, W. P. West, J. Nucl. Mater., 2003, 313-316, 214.

[142] Y. Oya, H. Kodama, M. Oyaidzu, Y. Morimoto, M. Matsuyama, A. Sagara, N. Noda, K. Okuno, J. Nucl. Mater., 2004, 329-333, 870.

[143] H. Kodama, M. Oyaidzu, A. Yoshikawa, H. Kimura, Y. Oya, M. Matsuyama, A. Sagara, N. Noda, K. Okuno, J. Nucl. Mater., 2005, 337-339, 649.

[144] H. Sugai, H. Toyoda, K. Nakamuta, K. Furuta, M. Ohori, K. Toi, S. Hirokura, K. Sato, J. Nucl. Mater., 1995, 220-222, 254.

[145] S. Kato, M. Watanabe, H. Toyoda and H. Sugai J. Nucl. Mater., 1999, 266269, 406.

[146] Y. Furuyama, K. Ito, S. Dohi, A. Taniike, A. Kitamura, J. Nucl. Mater., 2003, 313-316, 288.

[147] H. Yagi, H. Toyoda, H. Sugai, J. Nucl. Mater., 2003, 313-316, 284.

[148] F. L. Tabarés, D. Tafalla, I. Tanarro, V. J. Herrero, A. Islyaikin and C. Maffiotte, Plasma Phys. Control. Fusion., 2002, 44, L37.

[149] F. L. Tabarés, V. Rohde and the Asdex upgrade team. Plasma Phys. Control. Fusion, 2004, 46, B381. 
[150] F. L. Tabarés, D. Tafalla, V. Rohde, M. Stamp, G. Mathews, G. Esser, V. Philipps, R. Doerner, M. Baldwin, J. Nucl. Mater., 2005, 337-339, 867.

[151] W. Jacob, C. Hopf , M. Schlüter, Appl. Phys. Lett., 2005, 86, 201103.

[152] W. Jacob, C. Hopf, M. Schlüter, T. Schwarz-Selinger, C. Sun. Optimisation of hydrocarbon redeposition reduction by tokamak-compatible scavenger techniques. EFDA Task TW3-TPP-SCAVOP, subtask 2. Final report, 2004.

[153] H. Liang, B. Shi, A. Fairchild, T. Cale, Vacuum, 2004, 73, 317.

[154]P. K. Chu, J. Y. Chen, L. P. Wang, N. Huang, Materials Science and Engineering, 2002, $R$ 36, 143.

[155] M. Laroussi, Plasma Process. Polym., 2005, 2, 391.

[156] C. P. Klages, Mat.-wiss. u. Werkstofftech. 1999, 30, 767.

[157] R. Förch, Z. Zhang, W. Knoll, Plasma Process. Polym., 2005, 2, 351.

[158] A. Ohl , K. Schröder, Surf. and Coat. Technol., 1999, 116, 820.

[159] F. Z. Cui, D. J. Li, Surf. Coat. Technol., 2000, 131, 481.

[160] P. Favia, R. D’Agostino, Surf. Coat. Technol., 1998, 98, 1102. 


\section{Figures}

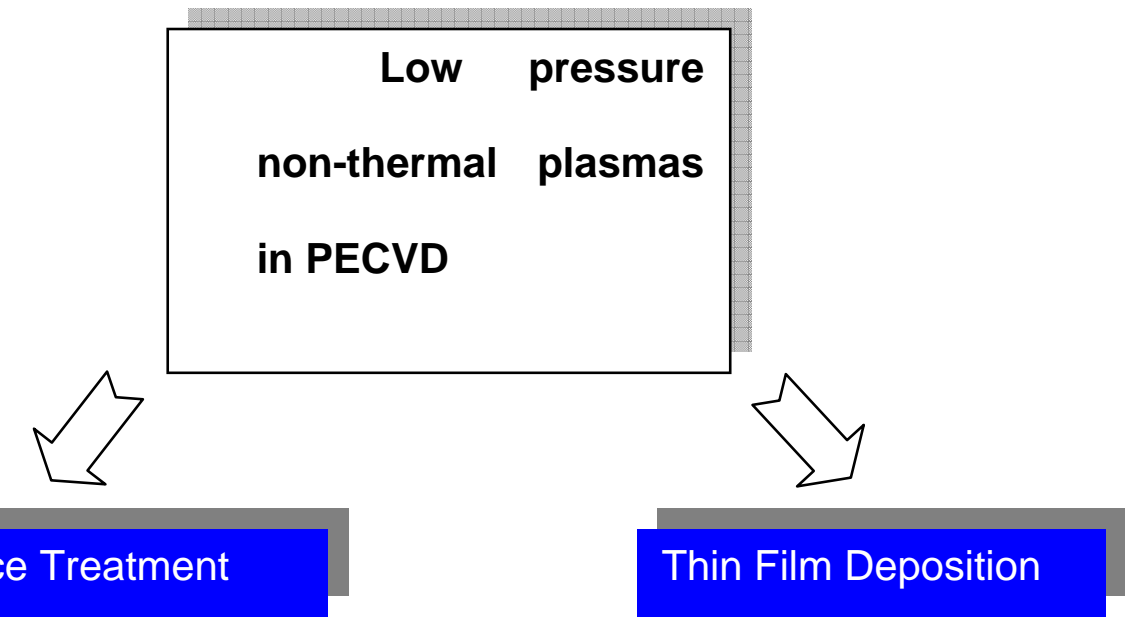

Figure 1: Main features of the plasmas produced in low pressure PECVD and applications. 


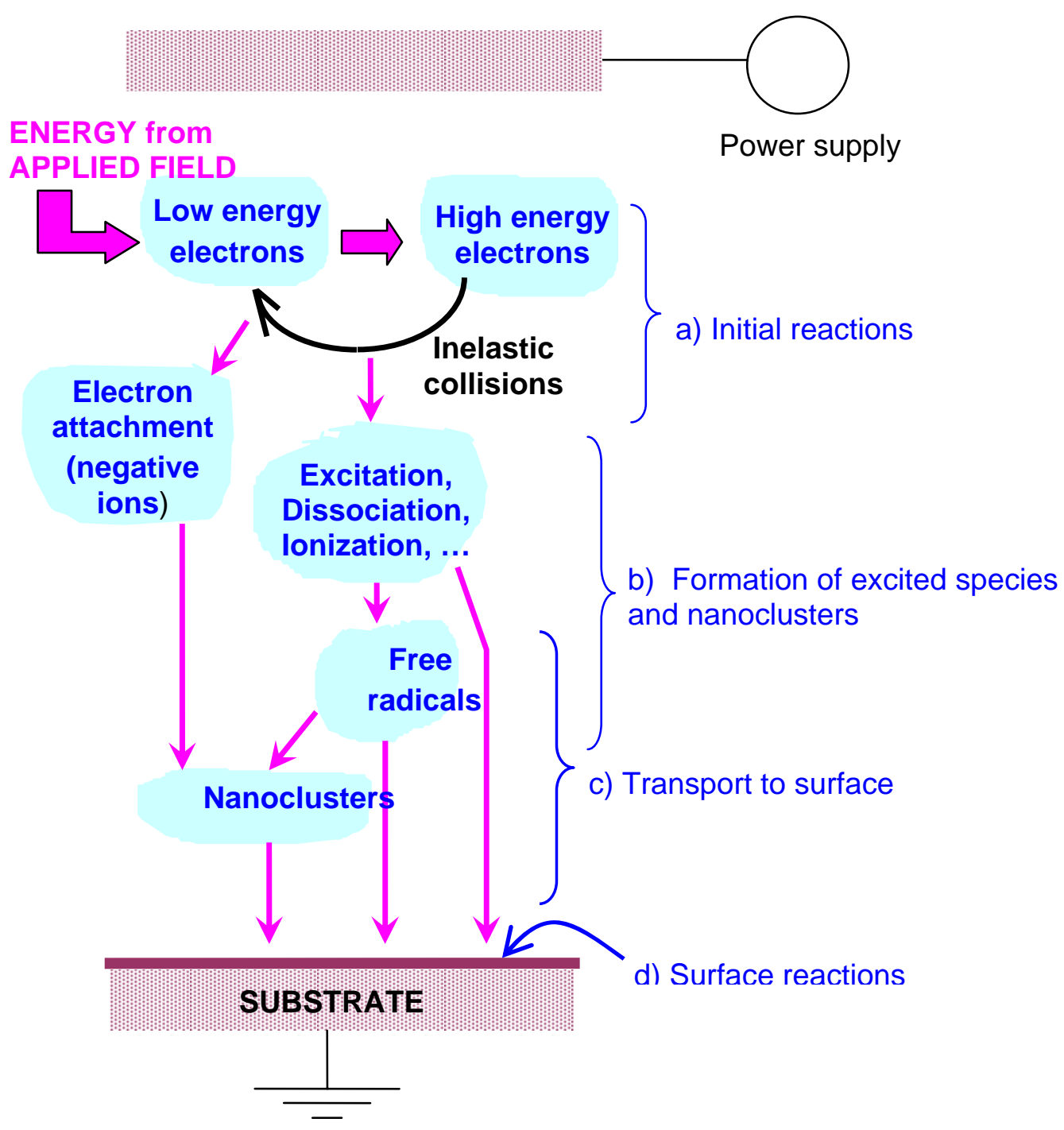

Figure 2: Sketch of processes taking place during low pressure PECVD. 


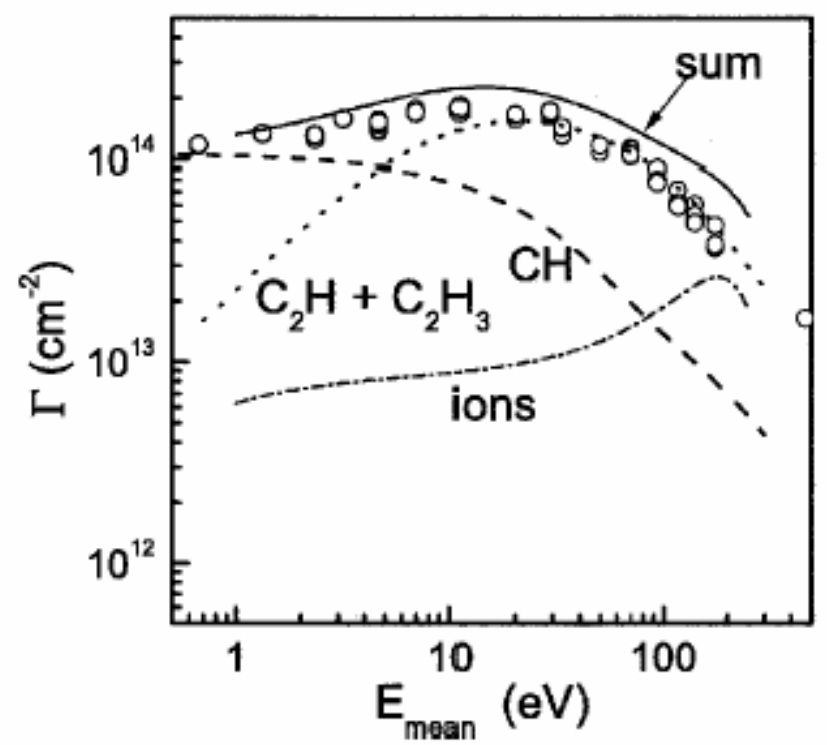

Figure 3: Fluence of incorporated carbon atoms per cycle $\Gamma_{\text {growth }}$ deposited in a methane ICP at $2 \mathrm{~Pa}$ (open circles) as a function of $\mathrm{E}_{\text {mean }}$ compared with the growth contribution per cycle of $\Gamma_{\mathrm{CH}}$ (dashed line), $\Gamma_{\mathrm{C} 2 \mathrm{H}}+\Gamma_{\mathrm{C} 2 \mathrm{H} 3}$ (dotted line), and $\Gamma_{\mathrm{C}}$ in $\mathrm{CnHm}^{+}$(dash-dotted line). The solid line represents the sum of the three contributions. (Reused with permission from M. Bauer, T. Schwarz-Selinger, W. Jacob, and A. von Keudell, Journal of Applied Physics, 98, 073302 (2005). Copyright 2005, American Institute of Physics). 


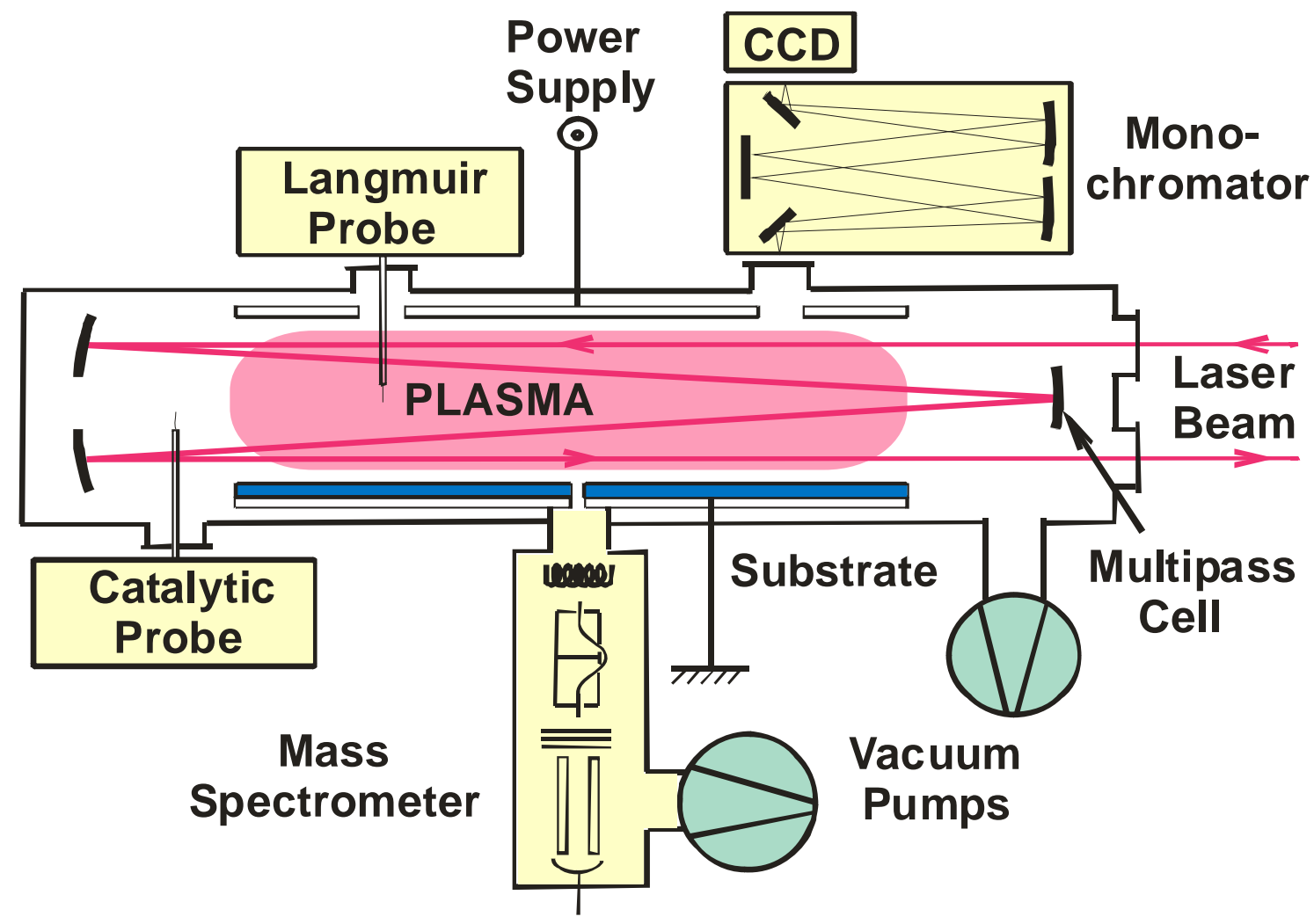

Figure 4: Simplified scheme of a PECVD reactor showing some of the different plasma diagnostic techniques mentioned in the text. 

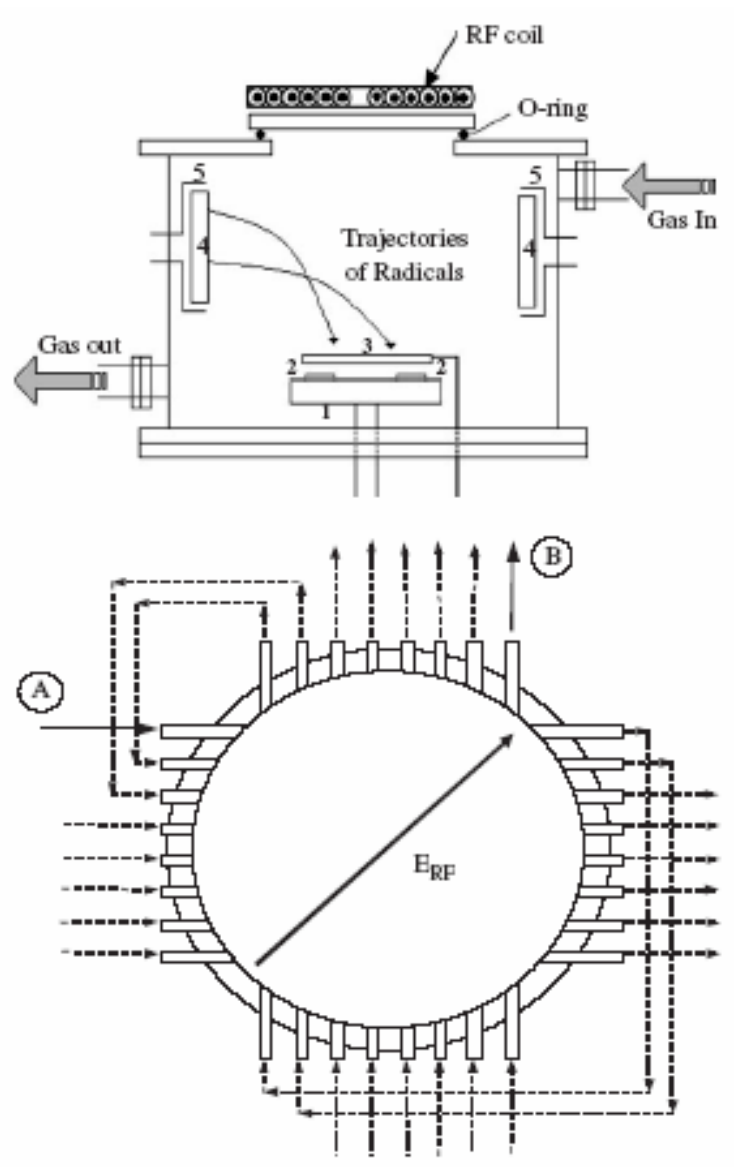

Figure 5: Schematics of an integrated plasma-aided nanofabrication facility (IPANF) comprising low-frequency inductively coupled plasma-assisted, lowpressure and multiple-target RF magnetron sputtering plasma source. Here, (1) substrate holder; (2) substrates; (3) shutter; (4) target; (5) target holder/electrode. Alternative configuration for the top section of the chamber (lower figure). Here, A and B denote the antenna connection points to the RF generator. (Figure reprinted from Vacuum, 80, S. Xu, K. Ostrikov, J. D. Long, S. Y. Huang, "Integrated plasmaaided nanofabrication facility: Operation, parameters, and assembly of quantum structutes and functional nanomaterials”, 621-630, Copyright 2006, with permission from Elsevier. 


\section{Chronology of carbon - based films by PECVD}

1976 First reports on carbonaceous films

1985 Polycrystalline diamond films

1989 Nanocrystalline diamond films

1994 Diamond films from Ar- $\mathrm{C}_{60}$ plasmas

1994 Ultrananocrystalline diamond (UNCD)

1997 Well aligned carbon nanotubes

2001 Nitrogen-doped UNCD

2005 Aligned carbon nanotips

2005 Hybrid of UNCD and carbon nanotubes

Figure 6: Brief chronology of carbon-based films by low pressure PECVD. 
(a)

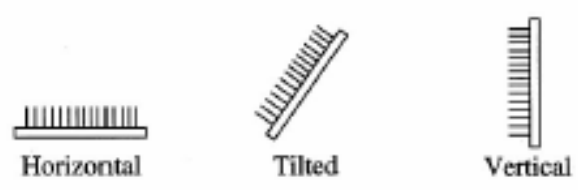

(b)

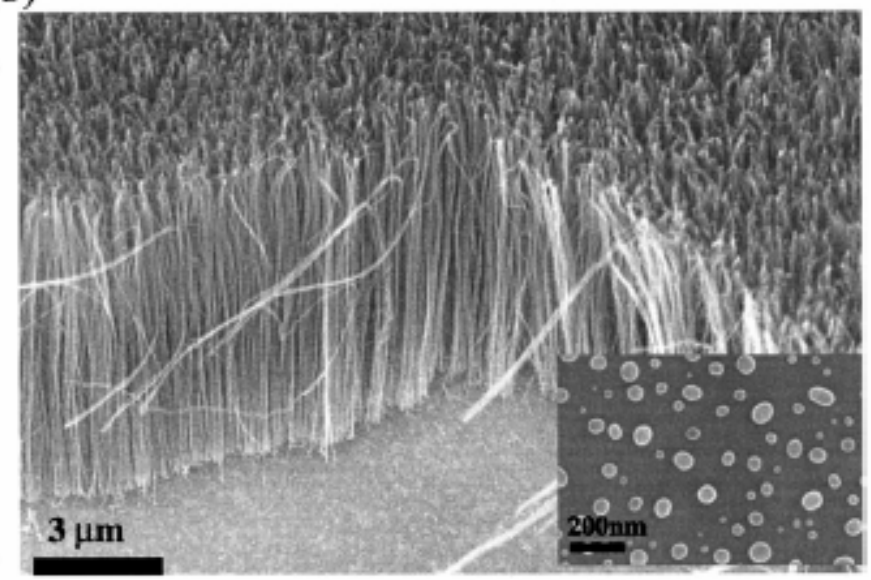

(c)

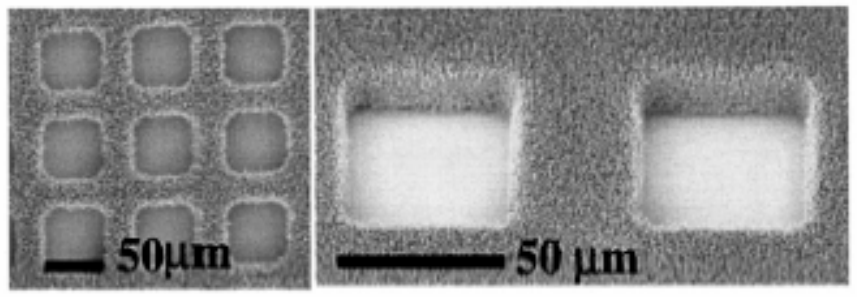

Figure 7: (a) Schematics showing the perpendicular alignment of nanotube growth regardless of the substrate position. (b) SEM image showing the growth of the well aligned nanotubes. The inset shows the cobalt islands that formed prior to the nanotube growth. (c) SEM images showing patterned nanotube growth as a result of patterning the cobalt catalyst prior to the growth. (Reused with permission from Chris Bower, Wei Zhu, Sungho Jin and Otto Zhou, Applied Physics Letters, 77, 830 (2000). Copyright 2000, American Institute of Physics). 


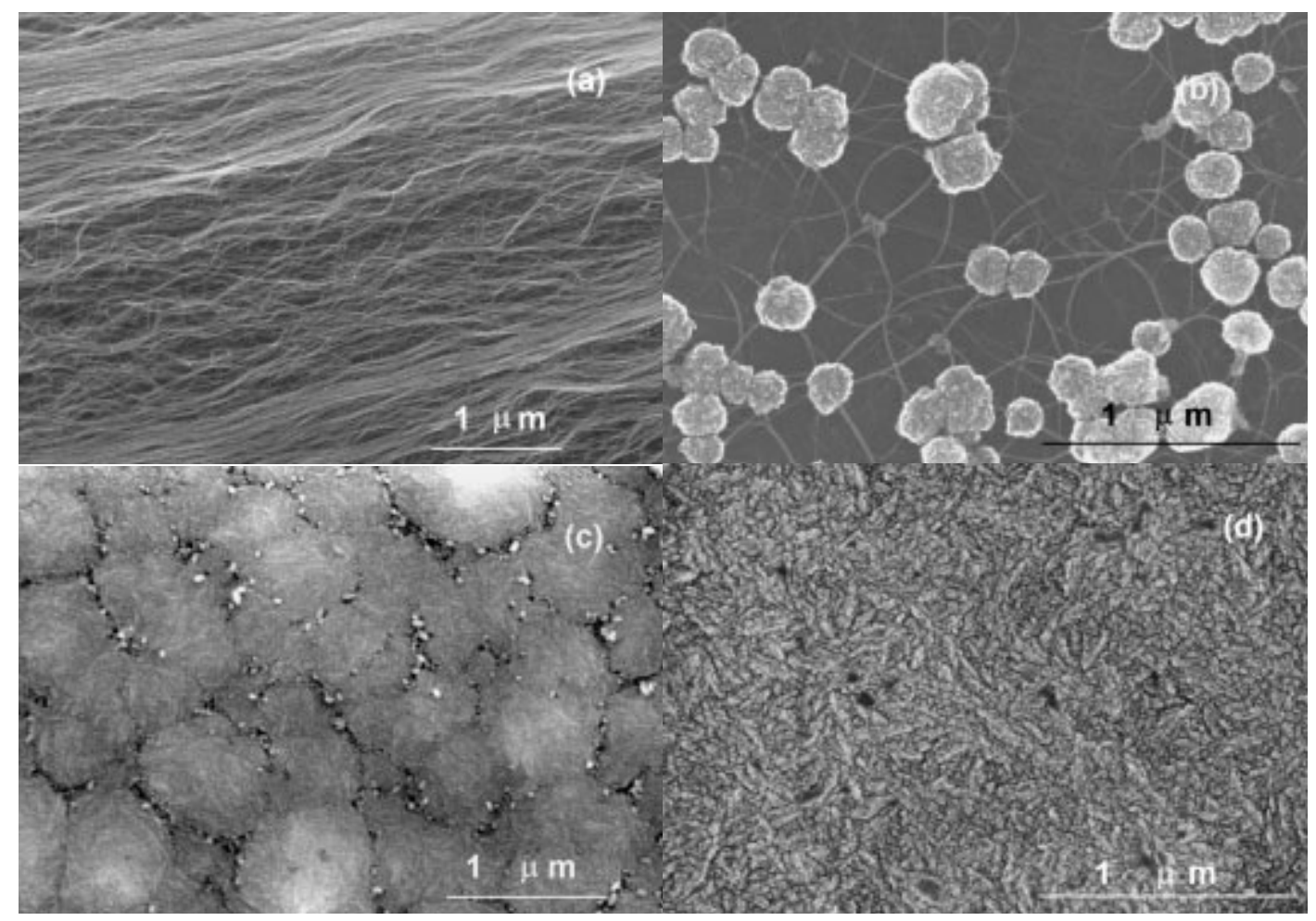

Figure 8: SEM pictures showing the evolution of a hybrid UNCD/CNT structure by varying the relative fraction of catalyst and nanodiamond seeds. a) Pure CNTs, b) Hybrid structure with a low fraction of CNTs and UNCD, c) A nearly fully dense hybrid structure of UNCD and CNTs with a high fraction of UNCD, d) Pure UNCD. (Adapted with permission from ref. 117) 


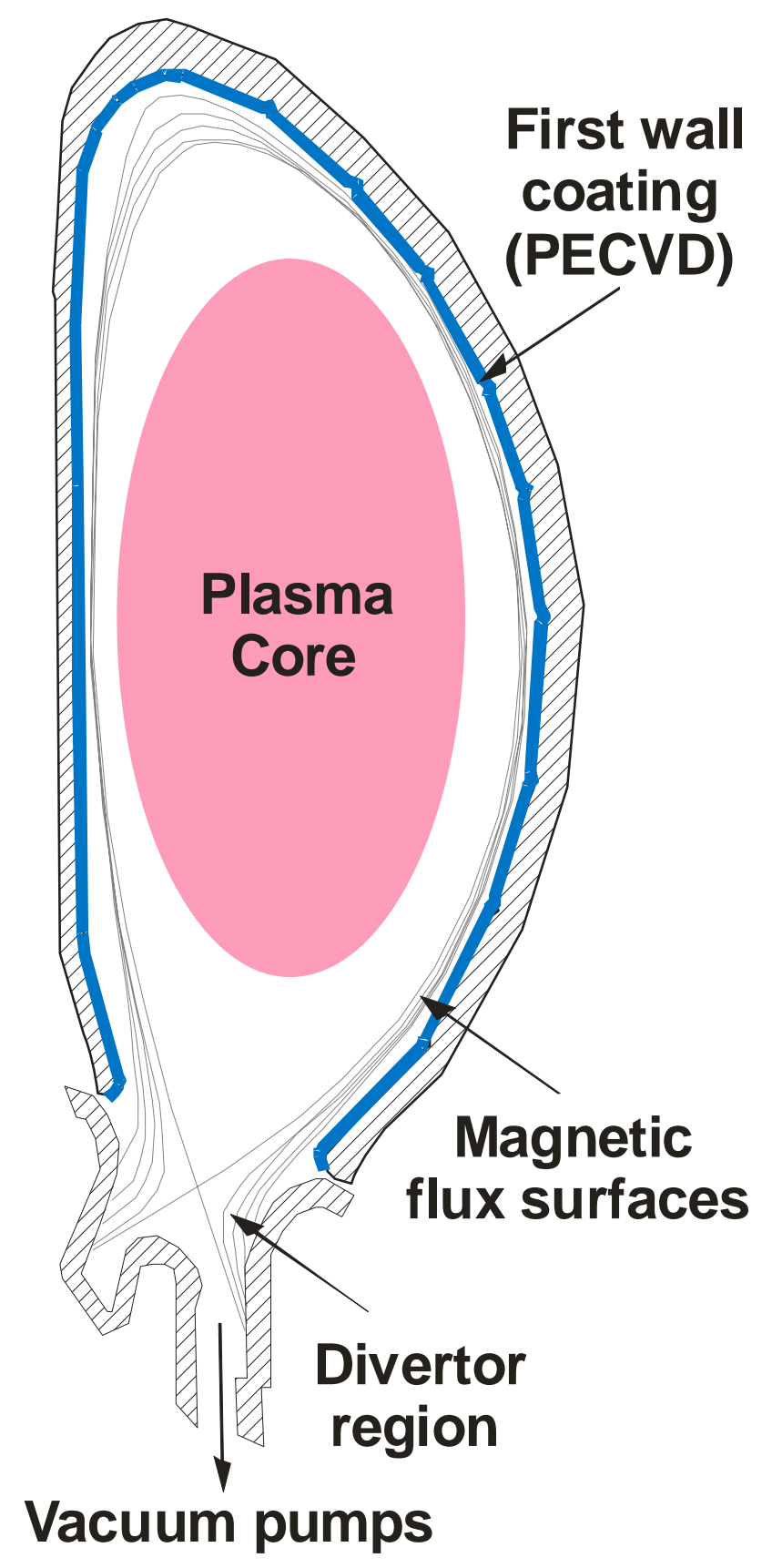

Figure 9: Poloidal cross section of a tokamak plasma showing the location of low Z coatings (by low pressure PECVD). 